Spannendes Programm: Interprofessioneller Gesundheitskongress

\section{Arzt und Pflegende: Hand in Hand}

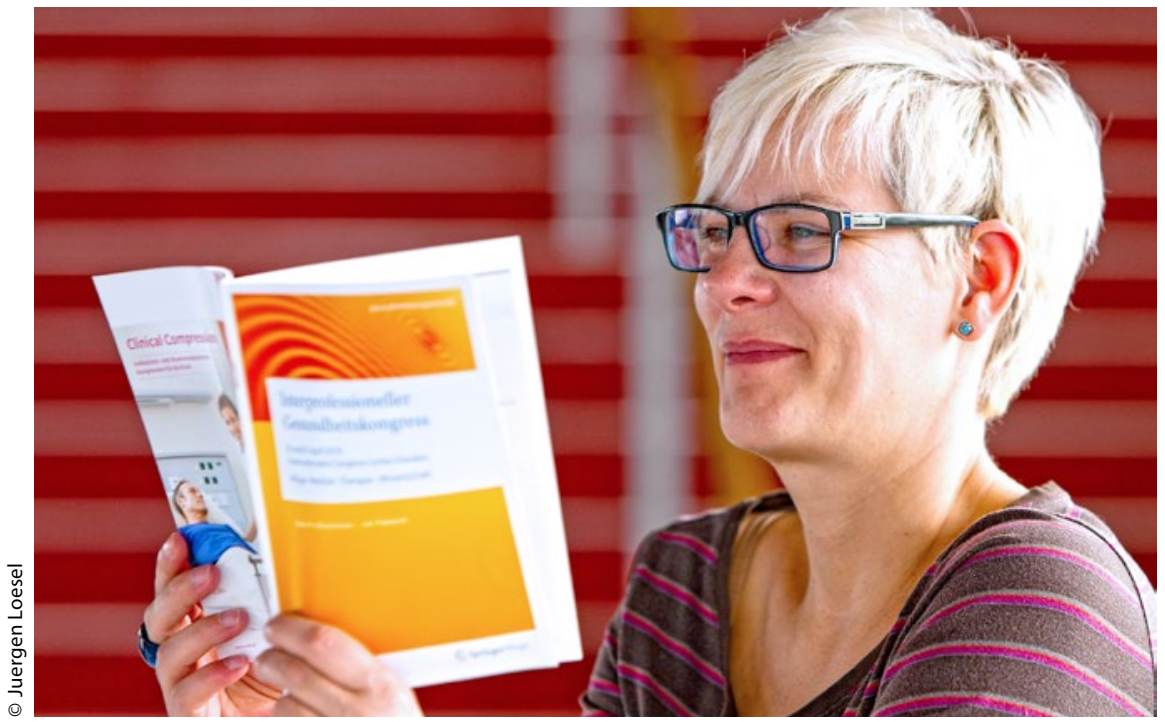

_ Am 8. und 9. April 2016 fand in Dresden zum vierten Mal der Interprofessionelle Gesundheitskongress statt, der vom Springer Medizin Verlag GmbH veranstaltet wurde. Erstmals tagten die rund 800 Besucher im Internationalen Congress Center Dresden.

"Alle gemeinsam, Hand in Hand, das wird immer wichtiger, um die medizinische Versorgung dauerhaft zu sichern", so die sächsische Ministerin für Soziales und Verbraucherschutz Barbara Klepsch (CDU) bei der Eröffnung des Kongresses. Die Neuausrichtung der Pflegeausbildung sei ein erster Schritt in die richtige Richtung, da es interprofessionelle Kompetenzen als Ausbildungsziel definiere.

Hedwig François-Kettner, Vorsitzende des Vorstandes des Aktionsbündnis Patientensicherheit (APS) betonte, dass Patientensicherheit ein gesellschaftlich akzeptierter Wert und integraler Bestandteil der Versorgung ist. Die Positionen des APS zur interprofessionellen Zusammenarbeit sind eindeutig: Die Förderung und Weiterentwicklung der Patientensicherheit brauche unter anderem Kommunikation auf Augenhöhe und eine Kultur des voneinander Lernens. Angeregte Diskussionen gab es in der Session „Pflege in Zukunft - Neuer Pflegeberuf und mehr Mitbestimmung?!". Neben den interprofessionellen Veranstaltungen gab es aber auch spezielle Module für Pflegefachkräfte, Ärzte und MTA. Das HeilberufeSCIENCE-Symposium bot mit Vorträgen und
Teilzeitarbeit in der Pflege Reserven mobilisieren

— Mehr als die Hälfte aller Beschäftigten in der Gesundheits- und Krankenpflege arbeitet in Teilzeit oder ist geringfügig beschäftigt. In einer aktuellen Studie hat das Institut Arbeit und Technik (IAT/Westfälische Hochschule) untersucht, ob und welche Arbeitskraftreserven in der Pflege mobilisiert werden könnten. Die IAT-Forscher analysierten persönliche Interessen und Motivationen von Pflegekräften, ihre Präferenzen zu Arbeitsbedingungen und -zeiten sowie Gründe für Teilzeitarbeit im Branchen- und Berufsvergleich. Etwa ein Viertel der befragten Pflegekräfte zeigte sich an einer Aufstockung der Wochenstunden interessiert. Somit scheint den Experten zufolge ein Potenzial, die Beschäftigung auszuweiten, zwar vorhanden aber von den Befragten wenig favorisiert zu sein. Das Ziel, Reserven zu mobilisieren, hänge maßgeblich auch von den Arbeitsbedingungen ab, heißt es weiter. Dem sollte in der aktuellen Debatte um die Aufwertung von Pflegearbeit stärker Rechnung getragen werden. In den Einrichtungen sollten laut IAT Gestaltungsoptionen erprobt werden, die einen flexibleren Personaleinsatz verknüpfen. Hier könnten Arbeitsbereiche mit einem breiteren Einsatzfeld und reduzierten Belastungen entstehen.

www.iat.eu

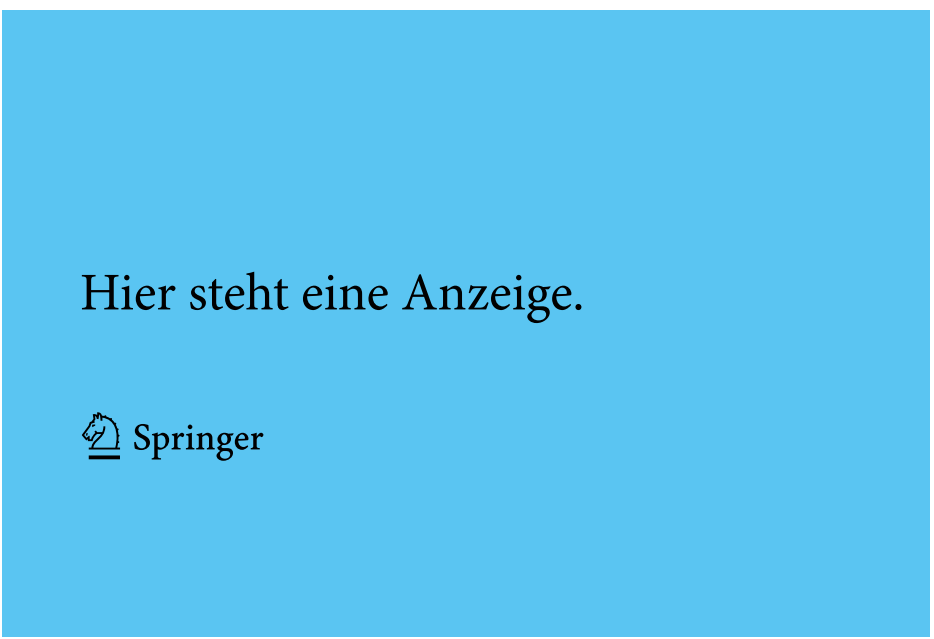

